\title{
Influence of scale and resolution on niche apportionment rules in saltmeadow vegetation
}

\author{
Barbara J. Anderson ${ }^{1,2, *}$, David Mouillot ${ }^{3}$ \\ ${ }^{1}$ Botany Department, University of Otago, PO Box 56, Dunedin, New Zealand \\ ${ }^{2}$ Department of Biology (Area 18), University of York, PO Box 373, YO10 5YW, York, UK \\ ${ }^{3}$ UMR CNRS-UMII 5119 Ecosystèmes Lagunaires, Université Montpellier II CC 093, 34095 Montpellier Cedex 5, France
}

\begin{abstract}
Stochastic niche apportionment models use a simple rule-based approach to simulate the process of community structure. These models were used to seek a general rule of community structure by investigating saltmeadow vegetation from New Zealand, South America and southern Europe. The patterns of relative abundances generated by 5 such models were then compared to those observed in the vegetation at both the community and intercontinental spatial scale. A randomization test was used to compare both the mean and variance of the ranks of the relative abundance distributions generated by Tokeshi's 5 niche apportionment models with those of the observed data. Three of the 5 models produced patterns that were significantly different to the observed pattern at all sites, scales and resolutions. Higher resolution made some improvement in the discrimination between the models, but did not alter the general trend. The random fraction (RF) model fitted the saltmeadow vegetation at the intercontinental scale and 5 of the 6 saltmeadow sites at the community scale. This suggests that hierarchical structuring and biotic interactions may play a role in the structuring of saltmeadow communities. The consistent results at widely different spatial scales, and from sites with different species composition and history, suggest the possibility of a general rule of community structure. By allowing the mean and the variance generated by a specific model to be compared with that of the observed community, mechanistic niche-apportionment models offer a step forward in our understanding of the processes that may structure communities.
\end{abstract}

KEY WORDS: Salt marsh $\cdot$ Community structure $\cdot$ Tokeshi $\cdot$ New Zealand $\cdot$ Chile $\cdot$ Corsica $\cdot$ Italy Randomization test

Resale or republication not permitted without written consent of the publisher

\section{INTRODUCTION}

Community structure and the question of coexistence of species have produced one of the most enduring and prominent themes of ecology (Hutchinson 1957, MacArthur 1972, Stubbs \& Wilson 2004). Many of the hypotheses put forward as explanations of why species are able to coexist centre on the niche concept (e.g. Hutchinson 1961, MacArthur \& Levins 1967, Tilman 2004). We investigate the question of coexistence and community structure as a result of ecological processes in saltmeadow vegetation using relative abundance distributions and stochastic niche apportionment models. Saltmeadow vegetation was selected because it is a classic harsh environment and considerable controversy surrounds the nature of biotic interactions, and hence community structure, in stressful or harsh environments (e.g. Terborgh 1973, Wiens 1977, Grime 1979, Callaway 1995, Chesson \& Huntly 1997); much of this debate centred on saltmeadow communities (e.g. Whittaker 1991, Bertness \& Hacker 1994, Emery et al. 2001, La Peyre et al. 2001, Stubbs \& Wilson 2004). To increase the generality of our conclusions, an inter-continental and multi-scale approach was used. Saltmeadow vegetation was sampled in 3 biogeographical regions, i.e. New Zealand, South America and southern Europe, and compared at both the community 
scale (within site) and at the intercontinental scale (across sites).

Niche apportionment models are classified as either deterministic models, those that give a single set of relative abundances, or stochastic models, those that encompass some degree of variation (Tokeshi 1990, Hubbell 2001). Early work was largely based on the fit of observed data to deterministic models, such as the broken-stick, geometric series, general lognormal, and Zipf-Mandelbrot (see Whittaker 1972, May 1975, Frontier 1985, Wilson 1991). These models are largely statistical in origin, and there are different biological interpretations for each model, so that if a model is shown to fit many different communities, it is unclear whether this is due to the model's flexibility or an underlying and general rule of community structure (May 1975, Tokeshi 1993). The different number of parameters required to fit the various models (Wilson 1991) further complicates objective comparison of these models. However, the main failing of deterministic models is that, as each model only has one realisation, it is possible to compare the mean of several observed replicates with the model prediction but not the variance. Stochastic mechanistic models may provide both a mean and a variance to compare with the observed data, and because they are mechanistic in nature, they have a greater potential to provide valuable insight into the processes behind community structure (e.g. Sugihara 1980, Tokeshi 1990, Mouillot et al. 2000, Hubbell 2001, Mouillot et al. 2003, Tilman 2004). Consequently, as niche-oriented models are explicitly related to an ecological process, they have an advantage over deterministic models, which have the inherent problem of requiring a post hoc ecological explanation. Following MacArthur (1957), niche-oriented models tend to be expressed in terms of a stick or unit volume which represents the total available resource of a community. This total resource is then divided amongst the species within the community following some mechanistic rule. In MacArthur's (1957) broken-stick model (Hypothesis I, non-overlapping niches) the total resource was divided simultaneously between the existing species, using a uniform random distribution. In contrast, the niche-apportionment models introduced and developed by Tokeshi (1990, 1993, 1996, 1999), and used here, all exhibit sequential division of the resources. Tokeshi argues this is a more ecologically realistic approach, as it is unlikely that all the species of a community would arrive simultaneously and then jostle for resources. Although Tokeshi (1990, 1993, 1996, 1999) suggests that his sequential MacArthur fraction (MF) model 'produces the same result as the broken-stick model', the average outcome of the 2 models is actually different. Despite the ready interpretability of the mechanistic approach of
Tokeshi, niche-apportionment models remain an inferential tool. Demonstrating that the species abundance pattern produced by a particular mechanism or division process is not significantly different from the observed pattern is not sufficient evidence to prove that the mechanism actually did produce the pattern only that it might have (Naeem \& Hawkins 1994). However the mechanistic niche-apportionment models do seem to offer a step forward in our understanding of which processes may produce community structure (Naeem \& Hawkins 1994, Tokeshi 1999).

Traditionally, niche-apportionment models have been fitted with either density data (e.g. Bersier \& Sugihara 1997) or biomass data (e.g. Mouillot et al. 2003) or both (Tokeshi 1990). To date, Tokeshi's models have not been used with vascular plant communities. One possible reason for this is that both biomass and density data are time-consuming and difficult to collect for most plant communities. Although some authors have suggested that biomass is the only appropriate abundance measure for community structure work (e.g. Wilson 1991), it is inappropriate to directly measure biomass in most natural systems as it destroys the system it seeks to conserve and becomes impractical when the biomass is too great (e.g. forest). Moreover, the measurement of density is also problematic, not only because of the considerable variation in individual size (Mouillot et al. 2003) but also because of the difficulty in defining an individual in plant communities that contain clonal species or modular individuals. Some authors (e.g. Mason et al. 2002) have suggested counting modules (e.g. leaves, ramets or tillers) rather than individuals; however, even these differ greatly in size and are often more time-consuming to count than individuals. Tokeshi (1993 p. 134) suggested that any measure of abundance that was deemed appropriate might be used. In studies of short vegetation, pointquadrat cover data provides a practical compromise. It is a time-efficient estimate of cover (Smartt et al. 1976) that is objective, does not require individuals of a species to be distinguished, and is non-destructive - an often crucial consideration in many conservation and/ or management studies (Glatzle et al. 1993). Critically, there is also evidence to suggest that cover is proportional to biomass or energy (e.g. Greig-Smith 1964, Sugihara 1989, Chiarucci et al. 1999, Guo 2001), and strong correlations have been found between density and cover data (e.g. Loya 1972).

Scale and resolution are 2 aspects of sampling that are particularly likely to affect the fit of field data to simulated models and consequently the perception of coexistence rules within communities. In this sense scale has been referred to as 'extent' (e.g. Palmer \& White 1994, Dungan et al. 2002). Resolution may be seen as the power or limits imposed by the sampling 
(Dungan et al. 2002). In order to evaluate the effect of scale and resolution on the fit of Tokeshi's niche-apportionment models to vascular plant communities, 2 levels of resolution and 2 scales were used: the intercontinental scale (observations across communities, where individual sites are the replicates); and the community scale (observations within communities, where quadrats within the individual sites are the replicates). The bounded nature of point-quadrat data means that it may be particularly sensitive to resolution (Greig-Smith 1964, Smartt et al. 1976). In the context of discrete bounded data the resolution is the range of possible abundances. With point-quadrat data the resolution of a site with replicate quadrats is equivalent to the number of points used in each quadrat. At the intercontinental scale resolution is still the number of points used in each quadrat (25 or 100), but a mean was taken over the 10 quadrats in each site. The importance of maintaining the same resolution has previously been recognised by Eilertsen et al. (1990), who used local frequency data combined with ordination gradients to investigate community structure. However, the influence of resolution on niche-oriented models does not appear to have been investigated. The impact of resolution on the final ecological conclusions may be particularly important when the resolution is low.

The aim of this study was to search for rules governing plant community structure using Tokeshi's nicheapportionment models. Saltmeadow vegetation from 3 biogeographical regions was used to uncover community structure rules. Two different levels of resolution and scale were used to test the robustness of both the method and any rules uncovered. Three specific questions were asked: (1) Can a niche-apportionment model fit observed plant data, and is there any consistency over different saltmeadow sites? (2) Does the fit to different niche-based coexistence rules depend on the resolution used to measure the species abundances? (3) Do the niche-based coexistence rules at the intercontinental scale mirror those of the community scale?

\section{MATERIALS AND METHODS}

Study system. Six saltmeadow sites were sampled in 3 biogeographical regions, New Zealand, Southern Europe and South America (Table 1, Anderson 2006). Sites included in the present study all fall in between the midtide line and the mean high-water neap-tide line and correspond roughly to what Partridge \& Wilson (1988) termed the 'middle marsh saltmeadow' or simply 'meadow'. Selliera radicans Cav., was among the dominant species at all the southern hemisphere sites. Both Selliera radicans and Samolus repens (Forster et Forster f,) Pers., were the dominant species at Mehuin, Queule, and Blueskin Bay; with the addition of Schoenus nitens (R. Br.) Hook. f. at the latter, and Selliera radicans alone at Savvedra. At Maremma, Halimione portulacoides (L.) Aell. was the dominant species; and at Porto Vecchio, Parapholis incurva C. E. Hubb., Athrocnemum macrostachya (Moric.) et Delponte, and Limonium vulgare

Table 1. General description of the 6 saltmeadow sites. Extent: dimensions of the sampling area; MAT: mean annual temperature; MAP: mean annual precipitation. For more detail on soil analyses and climate data used see Anderson (2006). N, P, K, pH and conductivity data are mean $\pm \mathrm{SD}$. Mean evenness was calculated using Molinari's (1989) $\mathrm{G}_{2,1}$ for both the 25 and the 100 resolution (res.) data. For full species taxonomy, see 'Materials and methods — study system'

\begin{tabular}{|c|c|c|c|c|c|c|c|c|c|c|c|c|c|}
\hline \multicolumn{14}{|c|}{ New Zealand } \\
\hline $\begin{array}{l}\text { Blueskin } \\
\text { Bay }\end{array}$ & $\begin{array}{l}\text { S. radicans } \\
\text { S. repens nitens }\end{array}$ & $40 \times 10$ & $\begin{array}{c}45^{\circ} 43^{\prime} \mathrm{S} \\
170^{\circ} 35^{\prime} \mathrm{E}\end{array}$ & 11 & 790 & $\begin{array}{c}1.4 \\
\pm 0.224\end{array}$ & $\begin{array}{c}22 \\
\pm 12.34\end{array}$ & $\begin{array}{c}79.4 \\
\pm 26.04\end{array}$ & $\begin{array}{c}5.43 \\
\pm 0.136\end{array}$ & $\begin{array}{l}24245 \\
\pm 4340\end{array}$ & 4.8 & 0.35 & 0.359 \\
\hline \multicolumn{14}{|c|}{ South America } \\
\hline Queule & $\begin{array}{l}\text { S. repens, } \\
\text { S. radicans }\end{array}$ & $20 \times 12$ & $\begin{array}{l}39^{\circ} 23^{\prime} \mathrm{S} \\
73^{\circ} 13^{\prime} \mathrm{W}\end{array}$ & 12 & 2330 & $\begin{array}{c}0.61 \\
\pm 0.212\end{array}$ & $\begin{array}{c}9.34 \\
\pm 2.475\end{array}$ & $\begin{array}{c}43.18 \\
\pm 10.93\end{array}$ & $\begin{array}{c}5.8 \\
\pm 0.209\end{array}$ & $\begin{array}{l}10555 \\
\pm 2491\end{array}$ & 9.4 & 0.341 & 0.356 \\
\hline Saavedra & S. radicans & $100 \times 25$ & $\begin{array}{c}38^{\circ} 56^{\prime} \mathrm{S} \\
73^{\circ} 30^{\prime} \mathrm{W}\end{array}$ & 12 & 2260 & $\begin{array}{c}0.13 \\
\pm 0.112\end{array}$ & $\begin{array}{c}3.27 \\
\pm 2.103\end{array}$ & $\begin{array}{l}25.66 \\
\pm 17.5\end{array}$ & $\begin{array}{c}5.84 \\
\pm 0.374\end{array}$ & $\begin{array}{c}9999 \\
\pm 7539\end{array}$ & 6.1 & 0.463 & 0.487 \\
\hline \multicolumn{14}{|l|}{ Europe } \\
\hline Maremma & H. portulacoides & $25 \times 6$ & $\begin{array}{l}43^{\circ} 47^{\prime} \mathrm{N} \\
11^{\circ} 13^{\prime} \mathrm{E}\end{array}$ & 14 & 638.9 & $\begin{array}{c}0.45 \\
\pm 0.065\end{array}$ & $\begin{array}{c}28.6 \\
\pm 3.89\end{array}$ & $\begin{array}{c}33.19 \\
\pm 5.377\end{array}$ & $\begin{array}{c}5.37 \\
\pm 0.295\end{array}$ & $\begin{array}{c}6216 \\
\pm 1747\end{array}$ & 3.9 & 0.397 & 0.401 \\
\hline
\end{tabular}


Mill. were dominant. Saltmeadow sites are subject to repeated inundation with saline water (Chapman 1960), and the main abiotic stress is therefore the high salinity of the soils (measured as soil conductivity). However, saltmeadow vegetation tends to be fairly stable, as it is generally associated with some kind of protection from the full forces of wind and sea: in estuaries, to landward of barrier islands or spits, in the lee of promontories and near extensive areas of shallow water (Chapman 1960). Both maritime/estuarine and brackish riverbank salt marshes were included in the present study. Maritime/ estuarine saltmeadows exist below the high-tide mark and are sheltered in some way from direct wave action (e.g. inside a semi-enclosed or shallow harbour or bay). Brackish riverbanks occur on the lower stretches of rivers, extending from the estuarine marshes to the upstream limit of seawater influence and the vegetation is mainly influenced by soil salinity. Lagoonal salt marsh and salt marsh with tall physiognomic dominants such as Avicennia resinifera Forster f. (woody mangrove) or Plagianthus divaricatus Forster et Forster f. (shore ribbonwood) were not included, nor were the species-poor and more disturbed lower marsh sites. Saltmeadows, especially estuarine saltmeadows, may be fairly productive due to the continuous deposition of sediment.

Sampling. Within each site 10 quadrats were located by restricted randomization; this ensured that samples were both an unbiased representation and spread over the area (Greig-Smith 1964). A soil sample was collected from the centre of each quadrat and analyzed for: total nitrogen (Kjeldahl method), available phosphorous (Olsen P method), available potassium (ammonium acetate, atomic absorption spectrophotometer method), conductivity (distilled water method), and $\mathrm{pH}$ (for details of soil analyses see Anderson 2006). Vascular plant species abundance was measured by point-quadrat cover. This satisfied 3 criteria as it is: (1) objective; (2) non-destructive; (3) with no requirement to distinguish individuals of the same species (Greig-Smith 1964, Smartt et al. 1976). These criteria effectively exclude subjective estimates of cover, the use of scales such as Braun-Blanquet and Domin, destructive and time consuming measures of biomass and productivity, and density or counts of individuals. For point-quadrat data, the presence or absence of each species is recorded at a number of points lowered vertically into a quadrat. These points 'if properly selected, are an unbiased sample of the infinitely large number of possible points and give an estimate of the true value of cover' (Greig-Smith 1964). Cover is generally expressed as a percentage, but, because each species is measured irrespective of the others, the total cover for a community may exceed 100. Point-quadrat cover was measured using 100 points placed by restricted randomization, in a $0.5 \times 0.5 \mathrm{~m}$ quadrat. The quadrat was first subdivided into 25 sub-quadrats, each $10 \times 10 \mathrm{~cm}$, within each of these sub-quadrats 4 points were randomly located. At each point a pin was lowered vertically, and all the species which the point touched were recorded as present. The number of hits for each species was summed over a quadrat.

The effect of resolution was compared using a resolution of 25 and a resolution of 100 . The resolution of 25 was achieved by removing 3 of the randomly located points from each of the $10 \times 10 \mathrm{~cm}$ sub-quadrats, so as to maintain the spatial structure and extent of the data but reduce the resolution. Two scales were compared. The community scale, using the quadrats as replicates within the sites $(n=10)$, and the intercontinental scale, using the individual sites as replicates $(n=6)$. At the intercontinental scale each species' abundance was calculated as the mean for the site using both the lower (25) and the higher (100) resolution.

Models. The 5 mechanistic niche-oriented models used here (dominance decay, DD; MacArthur fraction, $M F$; random fraction, $R F$; random assortment, $\mathrm{RA}_{\text {; }}$ and dominance pre-emption, DP) are those introduced and/or developed by Tokeshi (1990, 1993, 1996, 1999). These models are termed niche-oriented models because they envisage the species abundances being defined through a 2-stage process: division and translation. In the first stage, the total niche (represented by the whole stick) is divided into species niches by a division rule. In the second stage, species niches are translated into species abundances, with the abundance of each species being assumed to be proportional to the segment or length of the stick it was allocated in the previous division stage. In each model, the total niche is broken into as many segments as there are species in the sample. These 5 models represent a series of sequential breakage models that produce different species abundance patterns, depending on the method of choosing the next segment to be broken.

Dominance decay $(\boldsymbol{D D})$ : The DD model represents the most even of all the Tokeshi niche apportionment models. After the first random break the segment chosen to be divided is always the largest. Ecologically, this represents the new or 'invading' species always taking part of the niche of the most abundant species.

MacArthur fraction (MF): Tokeshi (1990, 1993, 1996, 1999) suggested that his MF model is analogous to MacArthur's (1957) broken stick model, but with sequential breakage rather than MacArthur's simultaneous breakage. Under Tokeshi's MF model, after the first random break, the segment to be divided is chosen at random, with the probability of choice proportion to the length of the segment. Ecologically, this is meant to represent a new or 'invading' species taking part of the niche of an existing one, with larger niches more likely to be invaded. 
Random fraction (RF): Tokeshi's RF model is similar to the MF model. However, after the first random break, the segment to be divided is chosen at random with each segment having an equal probability of being selected. This is the sequential breakage model of Sugihara (1980) and the sequential breakage algorithm type III of Naeem \& Hawkins (1994). It gives a lognormal distribution of abundances (Sugihara 1980). Ecologically, this represents a new or 'invading' species taking part of the niche of an existing species, with all the existing species equally likely to be invaded.

Random assortment (RA): The segment to be divided is chosen at random, and the other segment is preserved from further division. Ecologically, the preserved segment represents niche pre-emption by a species, the remaining part represents unoccupied niche space. According to Tokeshi (1990, 1993), this model may be seen as the result of either 'non-correspondence between niche apportionment and species abundance' or as 'non-hierarchical, dynamic apportionment of niche in a variable environment'. Tokeshi $(1990,1993)$ intended this as a 'null' or 'neutral' model where the abundances of the species varied independently of each other, the niche was assumed to be unsaturated and competitive relationships were not 'structuring' the community.

Dominance pre-emption (DP): The DP model represents the extreme opposite of the DD model. Under the DP model, after the first random break the segment chosen to be divided is always the smallest. This means that the largest segment produced at each division is preserved from further division, producing a high degree of dominance, i.e. low evenness. Ecologically, this represents resource pre-emption by a dominant species.

Fitting procedure. The procedure used to fit these models here is that used by (Mouillot et al. 2003). It is a modified and improved version of that first proposed by Tokeshi (1993). The method proposed by Tokeshi does not allow for the rejection of communities whose variance is larger than the one expected from the model, and it is sensitive to the number of species or ranks. Bersier \& Sugihara (1997) introduced a randomization test to overcome these problems. This procedure was further improved by Cassey \& King (2001). However, their procedure was species-oriented, i.e. species identities are assumed to be important. Thus, the mean and the variance of each species across the replicates produce the observed relative abundance distribution, which is then compared with the stochastically generated models. In contrast, the procedure used in the present study is process-oriented. The models assume no consistency in species ranks across replicates, the species of each replicate are ranked independently and the mean and variance for the rela- tive abundance of each rank are calculated across all replicates. These observed means and variances are then compared with the values generated by a large number of simulations (9999 in each case) according to each model. A model is considered not to be rejected when the p-value for both the mean and variance are greater than 0.05 (Mouillot et al. 2003). Although Tokeshi (1993) has argued that either interpretation might be equally valid, the process-oriented approach allows the examination of the relative abundance distribution to be separated from the question of rank consistency between the species - a concept which may be explicitly addressed using a distinct randomisation procedure (e.g. Mason et al. 2002).

\section{RESULTS}

The RF and RA models were the models which most often fitted both the mean and the variance (Table 2). At the community scale (within site) the RF model fitted 5 of the 6 saltmeadows with both the low resolution data (i.e. not Maremma) and the higher resolution data (i.e. not Blueskin Bay). The RA model fitted 4 of the 6 sites with both the low and high resolution. However, at the intercontinental scale only the RF model was accepted, all other models were significantly different from the observed data (Table 2). The DD, MF and DP models were significantly different $(p<0.05)$ to the species-abundance pattern of all 6 sites at both the community scale and the intercontinental scale, using both the low resolution (25) and the high resolution (100) (Table 2). To illustrate these results we chose to present data for the RF (Fig. 1) and RA (Fig. 2) models at the intercontinental scale with low resolution for both the means (Figs. 1a,c \& 2a,c) and the variances (Figs. 1b,d \& 2b,d). The observed relative abundance distribution for both the mean and variance of the observed data clearly fall well within the $95 \%$ confidence interval of the RF simulation model (Fig. 1a,b), but the tail end of the observations exceed the $95 \%$ confidence interval for the RA simulation model (Fig. 2a,b). This can be seen perhaps even more clearly from the frequency distribution of the test statistic values for the mean and the variance of the 2 simulations. The observed test statistic falls within the distribution for the RF model (Fig. 1c,d) but the observed statistic is an outlier when compared to the distribution for the RA model (Fig. 2c,d). Note that the test-statistic values are dependent on both the model and the observed values. Thus, it is normal to have different observed statistics for the same data but for 2 different models. The test-statistic includes a comparison to simulated distributions and is not $100 \%$ derived from the observed data. 
Table 2. Comparison of saltmeadow vegetation and Tokeshi's niche apportionment models. The models were: dominance decay (DD), MacArthur fraction (MF), random fraction (RF), random assortment (RA) and dominance pre-emption (DP). Comparison of the observed and simulated data is based on both the mean and variance of the relative abundances of the species ranks for saltmeadow vegetation at 2 scales and at 2 resolutions. At the community scale 6 saltmeadow sites were compared. Models that could not be rejected (both 2 -tailed mean and variance $p \geq 0.05$ ) are in bold: $p$ given for mean and variance (var.) where $p$ for the mean $>0.001 .^{*} \mathrm{p}<0.001$

\begin{tabular}{|c|c|c|c|c|c|c|c|c|c|c|c|}
\hline \multirow{2}{*}{$\begin{array}{l}\text { Scale } \\
\& \text { site }\end{array}$} & \multirow{2}{*}{ Resolution } & \multirow[b]{2}{*}{$\begin{array}{c}\text { DD } \\
\text { Mean }\end{array}$} & \multirow[b]{2}{*}{$\begin{array}{l}\text { MF } \\
\text { Var. }\end{array}$} & \multirow[b]{2}{*}{$\begin{array}{c}\text { RF } \\
\text { Mean }\end{array}$} & \multirow[b]{2}{*}{$\begin{array}{l}\text { RA } \\
\text { Var. }\end{array}$} & \multicolumn{2}{|c|}{ Model } & \multirow[b]{2}{*}{ Mean } & \multirow[b]{2}{*}{ Var. } & \multirow[b]{2}{*}{ Mean } & \multirow[b]{2}{*}{ Var. } \\
\hline & & & & & & $\begin{array}{c}\text { DP } \\
\text { Mean }\end{array}$ & Var. & & & & \\
\hline \multicolumn{12}{|l|}{ Community } \\
\hline Blueskin & 25 & & * & & * & 0.106 & 0.102 & 0.735 & 0.234 & & * \\
\hline Mehuin & 25 & & * & & * & 0.085 & 0.139 & 0.213 & 0.068 & & * \\
\hline Saavedra & 25 & & * & & * & 0.246 & 0.419 & \multicolumn{2}{|c|}{$*$} & \multicolumn{2}{|c|}{ * } \\
\hline Queule & 25 & & * & & * & 0.140 & 0.872 & 0.061 & 0.407 & \multicolumn{2}{|c|}{ * } \\
\hline Maremma & 25 & & * & \multicolumn{2}{|c|}{ * } & 0.011 & 0.111 & 0.010 & 0.039 & 0.001 & \multirow{2}{*}{ * 0.026} \\
\hline Porto Vecchio & 25 & & * & 0.002 & 0.271 & 0.259 & 0.233 ) & 0.133 & 0.183 & & \\
\hline Blueskin & 100 & & * & \multicolumn{2}{|c|}{$*$} & 0.012 & 0.071 & 0.113 & 0.097 & & * \\
\hline Mehuin & 100 & & * & \multicolumn{2}{|c|}{ * } & 0.311 & 0.136 & 0.667 & 0.057 & & * \\
\hline Saavedra & 100 & & * & \multicolumn{2}{|c|}{ * } & 0.357 & 0.069 & & & \multicolumn{2}{|c|}{ * } \\
\hline Queule & 100 & & * & \multicolumn{2}{|c|}{ * } & 0.108 & 0.720 & 0.047 & 0.901 & \multicolumn{2}{|c|}{ * } \\
\hline Maremma & 100 & & * & \multicolumn{2}{|c|}{ * } & 0.072 & 0.069 & 0.088 & 0.086 & \multicolumn{2}{|c|}{ * } \\
\hline Porto Vecchio & 100 & & $*$ & \multicolumn{2}{|c|}{ * } & 0.328 & 0.151 & 0.437 & 0.538 & \multicolumn{2}{|c|}{ * } \\
\hline \multicolumn{12}{|c|}{ Intercontinental } \\
\hline Saltmeadow & 25 & & * & & * & 0.552 & 0.160 & \multirow{2}{*}{0.002} & 0.001 & \multirow{2}{*}{\multicolumn{2}{|c|}{ * }} \\
\hline Saltmeadow & 100 & & $*$ & & * & 0.146 & 0.576 & & & & \\
\hline
\end{tabular}
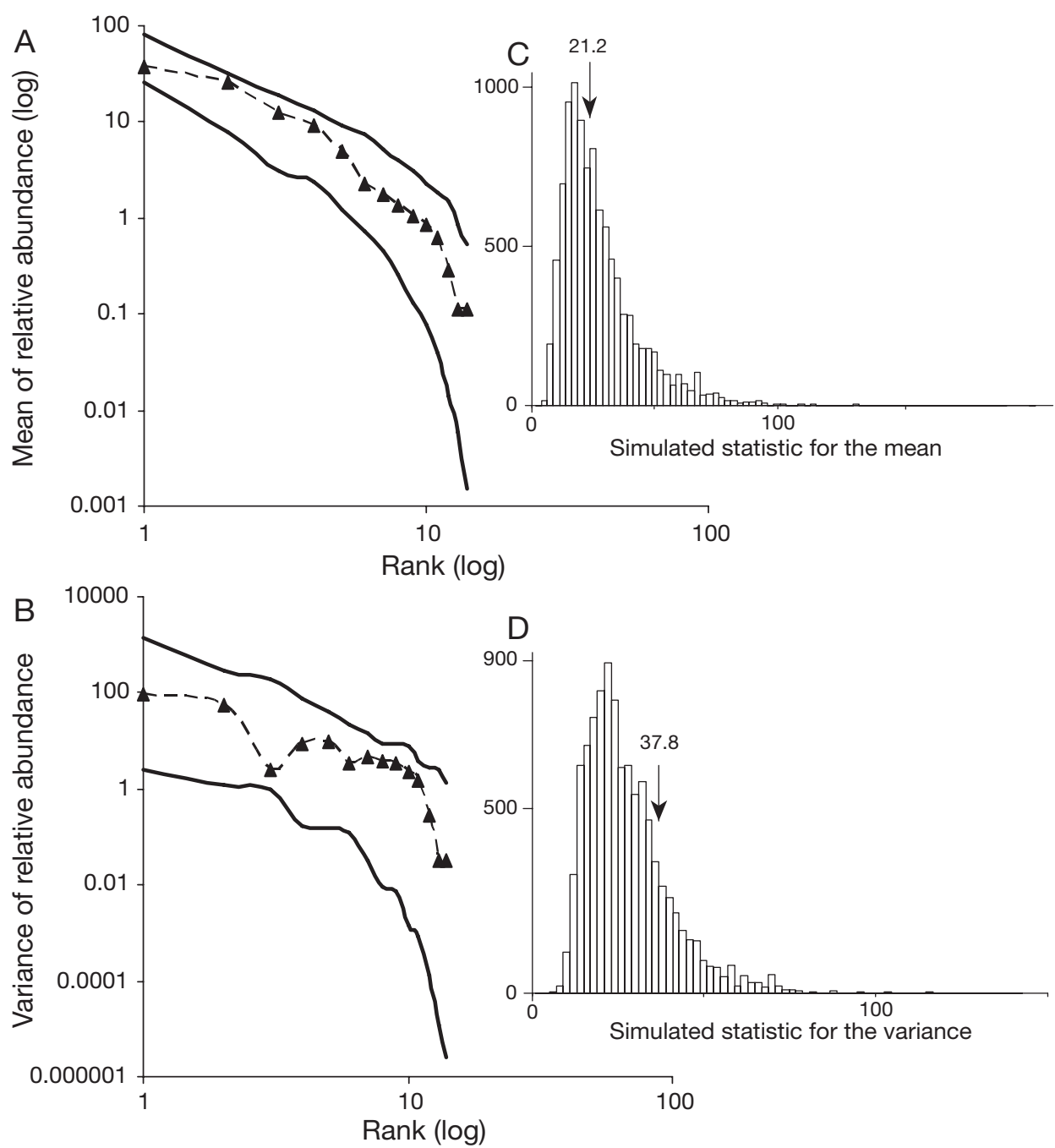

Fig. 1. Observed means (A) and variances (B) for the ranks at the intercontinental scale using the low (25) resolution $(\boldsymbol{\Delta}) ; 95 \%$ confidence intervals are given for the random fraction (RF) model (solid lines). Frequency distribution of the test statistic values for the mean $(\mathrm{C})$ and the variance (D) of the RF model produced by the randomization procedure; observed values are indicated by an arrow on the distribution and are not significantly different from the RF model, which therefore cannot be rejected 

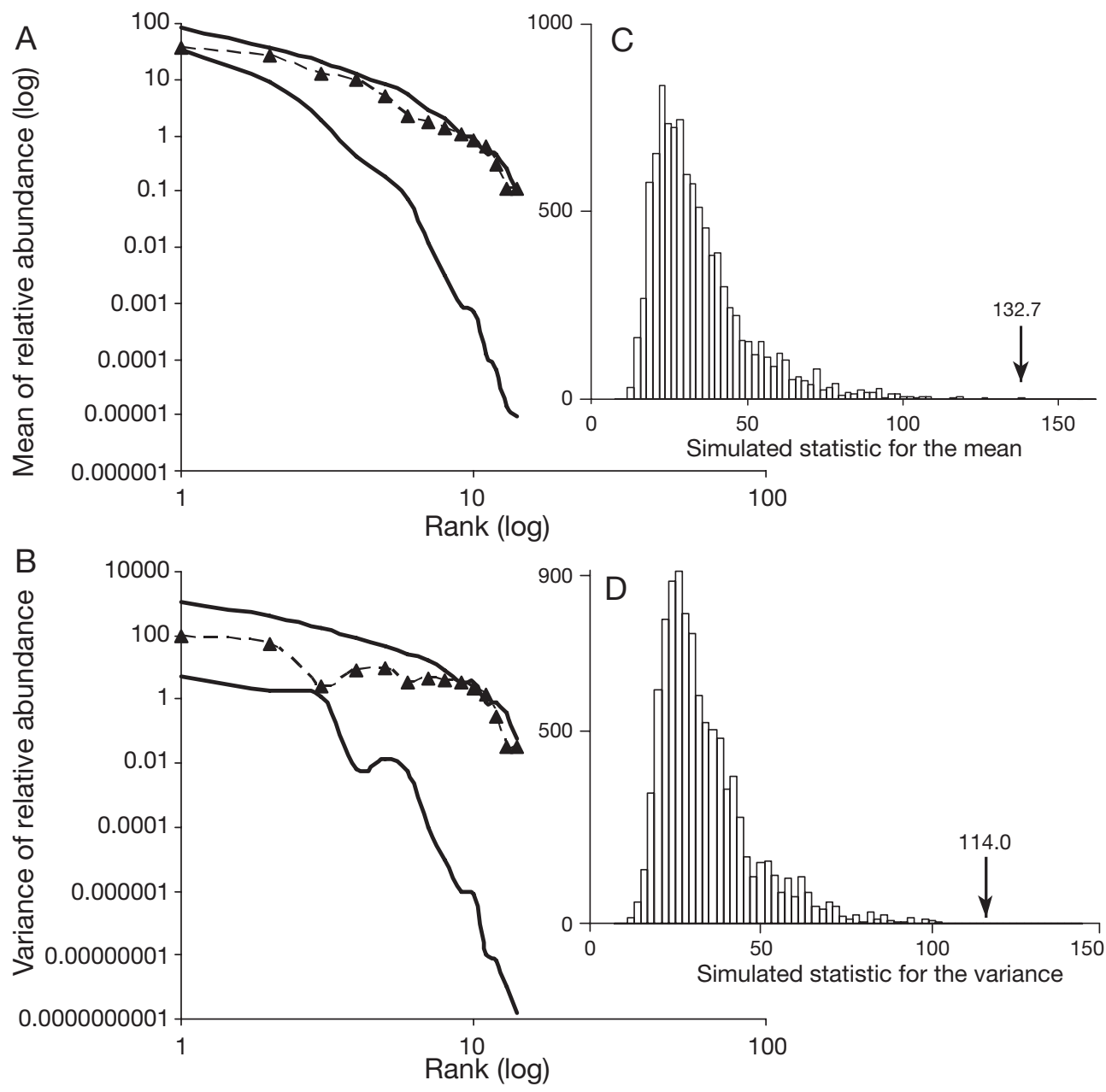

Fig. 2. Observed means (A) and variances (B) for the ranks at the intercontinental scale using the low (25) resolution $(\boldsymbol{\Delta})$; $95 \%$ confidence intervals are given for the random assortment (RA) model (solid lines). Frequency distribution of the test statistic values for the mean $(\mathrm{C})$ and the variance (D) of the RA model produced by the randomization procedure; observed values are indicated by an arrow on the distribution and are significantly different from the RA model, which therefore can be rejected

\section{DISCUSSION}

The RF and the RA models were accepted more often than the more extreme DD, MF or DP models. This is in general agreement with the findings of the few existing small-scale studies: epiphytic chironomid communities (Tokeshi 1990), larval chironomid assemblages (Fesl 2002), macrobenthic communities (Formentin et al. 1997), parasite communities (Mouillot et al. 2003), and parasitoid communities (Naeem \& Hawkins 1994).

\section{Resolution}

With the exception of the effect of sample size on density data (e.g. Simpson 1949, Peet 1975), the effect of resolution on various abundance measures and data analyses has not been well studied (Dungan et al. 2002). The bounded nature of point-quadrat data may make models particularly susceptible to the influence of resolution, but also allows the ecologist to predeter- mine and standardize the resolution used in samples or studies, thus allowing valid comparisons. Tests of the effects of resolution showed that higher resolution improved the discrimination between the models (Table 2) and higher resolution data resulted in the rejection of the RF model for Blueskin Bay and the RA model for Queule. However, with high resolution, both the RF and the RA models were accepted for Maremma whilst low resolution resulted in the rejection of all models for this site. This difference between the 2 levels of resolution may be related to the very low species richness of the site at Maremma (Table 1). However, at the intercontinental scale, all models except the RF were rejected at either resolution. This suggests that resolution may be more important at the smaller, community scale than at the larger, intercontinental scale. This may simply be an effect of statistical power. At the intercontinental scale there are more species per replicate and the relative abundance per replicate would also show less stochastic variation (since the relative abundance of each species would combine the data from all the quadrats from a site). 
The difference observed between the 2 scales of observation may therefore be largely due to sampling effort per se rather than an intrinsic effect of scale.

\section{Community scale}

At the community scale the RF model was accepted for 5 of the 6 saltmeadow communities at both the low and high resolution. The ecological interpretation of this model is that the niche or species to be 'invaded' is chosen at random with each available species equally likely to be chosen irrespective of its abundance (i.e. the size of its niche). Tokeshi (1996) suggests that this may be the result of 'species with narrow niches being more likely to pursue the tendency of specialization' balancing out the 'trend of species with a wider niche to experience a higher chance of habitat fragmentation and isolation' and therefore speciation (i.e. there is an equal likelihood that segments will be chosen from species with larger or smaller niches). Intuitively, the RF model seems to be a more realistic scenario than a model in which the abundances of the available species determines with which the 'invading' species competes, as is the case in the DD, DP and MF models. Ecologically, it seems more likely that an 'invading' species would compete with an available species that is most similar in resource use (MacArthur \& Levins 1967) rather than the most abundant species (DD), the least abundant species (DP) or proportionally more with more abundant species (MF). Fesl (2002) examined both species-oriented and process-oriented models. He found that only the RF model fitted his larval chironomid communities when he used the processoriented model and the entire community, as in the present study. Tokeshi (1990) found that the RF model fitted epiphytic chironomid communities when based on density but not biomass, while Naeem \& Hawkins (1994) found that the RF model fitted parasitoid communities. Ecologically, Tokeshi $(1990,1993)$ argues that the RF model suggests that there is some hierarchical structure, i.e. within the saltmeadow communities. If this is a general rule, then the same model may explain the relative abundance patterns of quite different communities. However, it has been shown that the RF model leads asymptotically to a lognormal distribution of abundances. Sugihara (1980) first brought to our attention the link between a random sequential breakage model (the RF model) and the lognormal distribution, and he suggested this was evidence for a hierarchical community structure. However, mechanisms other than a sequential breakage may also lead to a lognormal distribution of abundance. For instance, if the abundances of the species are determined by several variables acting multiplicatively but indepen- dently, this will also lead to a lognormal distribution (May 1975). Another example is the Unified Neutral Theory of Biodiversity and Biogeography proposed by Hubbell (2001), which shows that communities of functionally equivalent species undergoing random drift may in some circumstances display patterns of abundance distribution that are very close to lognormal. The multiplicity of potential mechanisms leading to the lognormal may explain why this distribution is so prevalent among ecological communities. Unfortunately, this also makes it impossible to determine which of these mechanisms is responsible without additional evidence.

Tokeshi $(1990,1993)$ suggests that the RA model may fit when there is no correspondence between the species niches and the species abundances or as a 'non-hierarchical, dynamic apportionment of niche under a highly variable environment'. However, if species abundances were not related to their niches, all 5 models should be rejected. In the present study, although the RF model was the most frequently accepted, the RA model was accepted for 4 of the 6 saltmeadow sites. Consequently, the ecological interpretation of the RA model must also be considered for some saltmeadow sites at the community scale. This model has previously been found to fit parasite communities in fishes (biovolume data; Mouillot et al. 2003) and in epiphytic chironomids (biomass and density data; Tokeshi 1990). Mouillot et al. (2003) suggested that the RA model was a suitable explanation for fish parasitoid communities because of their dynamic and unsaturated nature. Blueskin Bay was the only saltmeadow site for which the RA, but not the RF, model was accepted. This site had both the highest abiotic stress (measured by the conductivity of the soil) and the highest levels of nutrients (soil NPK; Table 1). The high nutrient levels at Blueskin Bay may reflect nutrient enrichment from the adjacent farmland and indicate that this site is more disturbed than the others. However, the RA model also fitted the 3 sites with the lowest conductivity: Mehuin, Maremma and Porto Vecchio (Table 1); whereas the remaining 2 sites, Saavedra and Queule, were rejected for the RA model but not the RF model.

\section{Intercontinental scale}

At the intercontinental scale, the 6 sites were used as replicates in order to determine whether there was evidence of a global pattern in the community structure of saltmeadow vegetation. Despite the very different species composition and vast spatial distance between the 6 sites, the RF model was the only model accepted, thus providing some evidence of a global pattern. The 
consistency of this result with that found at the community scale suggests the possibility of some element of self-similarity in the construction of saltmeadow vegetation. Saltmeadow is widely acknowledged to be a stressful or harsh abiotic environment due to its high salinity. C-S-R theory maintains that the importance of competition is reduced in stressed (including saline) habitats (Grime 1979). As the saltmeadow vegetation in the present study fits the RF model, hierarchical structuring of the community is likely, and this suggests that competition may play some part in community structure of at least some stress communities (cf. Naeem \& Hawkins 1994). Although one of the 6 saltmeadows rejected the $\mathrm{RF}$ model at the community scale, the saltmeadow vegetation as a whole fitted the RF model. This suggests that there may be a general rule, which may include biotic interactions, at least for saltmeadow vegetation. However, given the link between the RF model and the lognormal distribution of species abundance, this 'consistency' may only suggest that the law of large numbers is at play (i.e. a statistical explanation rather than a biological one). What is clear is that all of the extreme models (DD, MF and DP) were significantly different from all the observed data for both resolutions at both the community and the intercontinental scale.

Acknowledgements. B.J.A. thanks C. Jara-Vergara, R. Ohlemüller, N. Mason and J. Wilson for assistance in the field, C. Ramirez, A. Chiarucci, C. Lusk, M. L. Castelli and M. L. Pozzo Di Borgo for assistance in locating suitable sampling sites and P. Bannister, A. Chiarucci, J. Clark, V. Clarke, B. Lowe, C. Lusk, O. Missa, R. Ohlemüller, C. D. Thomas, and one anonymous reviewer for comments on the manuscript and invaluable discussion. We acknowledge a grant to B.J.A. from the Miss H. E. Hellaby Indigenous Grasslands Trust, BRAP, and a University of Otago Research Grant. B.J.A. was supported by a FORST Bright Future award, and UKPopNet.

\section{LITERATURE CITED}

Anderson BJ (2006) Something to do with community structure: the influence of sampling and analysis on measures of community structure. PhD dissertation, University of Otago, Dunedin

Bersier LF, Sugihara G (1997) Species abundance patterns: the problem of testing stochastic models. J Anim Ecol 66:769-774

Bertness MD, Hacker SD (1994) Physical stress and positive associations among marsh plants. Am Nat 144:363-372

Callaway RM (1995) Positive interactions among plants. Bot Rev 61:306-349

Cassey P, King RAR (2001) The problem of testing the goodness-of-fit of stochastic resource apportionment models. Environmetrics 12:691-698

Chapman VJ (1960) Salt marshes and salt deserts of the world. Interscience Publishers, London

Chesson P, Huntly N (1997) The roles of harsh and fluctuating conditions in the dynamics of ecological communities. Am Nat 150:519-553
Chiarucci A, Wilson JB, Anderson BJ, De Dominicis V (1999) Cover versus biomass as an estimate of species abundance: Does it make a difference to the conclusions? J Veg Sci 10:35-42

Dungan J, Perry JN, Dale MRT, Legendre P and others (2002) A balanced view of scale in spatial statistical analysis. Ecography 25:626-640

Eilertsen O, Okland R, Okland T, Pedersen O (1990) Data manipulation and the gradient length estimation in DCA ordination. J Veg Sci 1:261-270

Emery NC, Ewanchuk PJ, Bertness MD (2001) Competition and salt-marsh plant zonation: Stress tolerators may be dominant competitors. Ecology 82:2471-2485

Fesl C (2002) Niche-orientated species-abundance models: different approaches of their application to laval chironomid (Diptera) assemblages in a large river. J Anim Ecol 71:1085-1094

Formentin JM, Dauvin JC, Ibanez F, Dewarumez JM, Elkaim B (1997) Long-term variations of four macrobenthic community structures. Oceanol Acta 20:43-53

Frontier S (1985) Diversity and structure in aquatic ecosystems. Oceanogr Mar Biol Annu Rev 23:253-312

Glatzle A, Mechel A, Vaz Lourenco ME (1993) Technical notes: botanical components of annual Mediterranean grassland as determined by point-intercept and clipping methods. J Range Manag 46:271-274

Greig-Smith P (1964) Quantitative plant ecology. Butterworths, London

Grime J (1979) Plant strategies and vegetation processes. Wiley, Chichester

Guo Q (2001) Early post-fire succession in California chaparral: changes in diversity, density, cover and biomass. Ecol Res 16:471-485

Hubbell SP (2001) The unified theory of biodiversity and biogeography. Princeton University Press, Princeton, NJ

Hutchinson GE (1957) Concluding remarks. Cold Spring Harbour Symp Quant Biol 22:415-427

Hutchinson GE (1961) The paradox of the plankton. Am Nat 95:137-145

La Peyre MKG, Grace JB, Hahn E, Mendelssohn IA (2001) The importance of competition in regulating plant species abundance along a salinity gradient. Ecology 82:62-69

Loya Y (1972) Community structure and species diversity of hermatypic corals at Eilat, Red Sea. Mar Biol 13:100-123

MacArthur RH (1957) On the relative abundance of bird species. Proc Natl Acad Sci USA 43:293-295

MacArthur RH (1972) Geographical ecology. Harper and Row, New York

MacArthur RH, Levins R (1967) The limiting similarity, convergence, and divergence of coexisting species. Am Nat 101:377-385

Mason NWH, MacGillivray K, Steel JB, Wilson JB (2002) Do plant modules describe community structure better than biomass? A comparison of three abundance measures. J Veg Sci 13:185-190

May RM (1975) Patterns of species abundance and diversity. In: Cody ML, Diamond JM (eds) Ecology and evolution of communities. Harvard University Press, Cambridge, MA, p 81-120

Molinari J (1989) A calibrated index for the measurement of evenness. Oikos 56:319-326

Mouillot D, Lepretre A, Andrei-Ruiz MC, Viale D (2000) The Fractal Model: a new model to describe the species accumulation process and relative abundance distribution (RAD). Oikos 90:333-342

Mouillot D, George-Nascimento M, Poulin R (2003) How parasites divide resources: a test of the niche apportionment 
hypothesis. J Anim Ecol 72:757-764

Naeem S, Hawkins BA (1994) Minimal community structure: how parasitoids divide resources. Ecology 75:79-85

Palmer MW, White PS (1994) Scale dependence and the species-area relationship. Am Nat 144:717-740

Partridge TR, Wilson JB (1988) Vegetation patterns in salt marshes of Otago, New Zealand. NZ J Bot 26:497-510

Peet RK (1975) Relative diversity indices. Ecology 56:496-498

Simpson E (1949) Measurement of diversity. Nature 163:688

Smartt PFM, Meacock SE, Lambert JM (1976) Investigations into the properties of quantitative vegetational data: II. further data type comparisons. J Ecol 64:41-78

Stubbs WJ, Wilson JB (2004) Evidence for limiting similarity in a sand dune community. J Ecol 92:557-567

Sugihara G (1980) Minimal community structure: an explanation of species abundance patterns. Am Nat 116:770-787

Sugihara G (1989) How do species divide resources? Am Nat 133:458-463

Terborgh J (1973) On the notion of favorableness in plant ecology. Am Nat 107:481-501

Tilman D (2004) Niche tradeoffs, neutrality, and community structure: a stochastic theory of resource competition,

Editorial responsibility: Howard Browman (Associate Editorin-Chief), Storebø, Norway invasion, and community assembly. Proc Natl Acad Sci USA 101:10854-10861

Tokeshi M (1990) Niche apportionment or random assortment: species abundance patterns revistied. J Anim Ecol 59:1129-1146

Tokeshi M (1993) Species abundance patterns and community structure. Adv Ecol Res 24:111-186

Tokeshi M (1996) Species coexistence and abundance: patterns and processes. In: Abe T, Levin LA, Higashi M (eds) Biodiversity: an ecological perspective. Springer, New York, p 35-55

Tokeshi M (1999) Species coexistence: ecological and evolutionary perspectives. Blackwell Science, Oxford

Whittaker RH (1972) Evolution and the measurement of species diversity. Taxon 21:213-251

Whittaker RJ (1991) Small-scale pattern - an evaluation of techniques with an application to salt-marsh vegetation. Vegetatio 94:81-94

Wiens JA (1977) On competition and variable environments. Am Sci 65:590-597

Wilson JB (1991) Methods for fitting dominance diversity curves. J Veg Sci 2:35-46

Submitted: June 18, 2007; Accepted: October 24, 2007

Proofs received from author(s): December 28, 2007 